\title{
Relationship between ulcer healing after hyperbaric oxygen therapy and transcutaneous oximetry, toe blood pressure and ankle-brachial index in patients with diabetes and chronic foot ulcers
}

\author{
M. Löndahl • P. Katzman • C. Hammarlund • \\ A. Nilsson • M. Landin-Olsson
}

Received: 25 April 2010 / Accepted: 1 September 2010 /Published online: 19 October 2010

(C) Springer-Verlag 2010

\begin{abstract}
Aims/hypothesis The randomised, double-blind, placebocontrolled Hyperbaric Oxygen Therapy (HBOT) in Diabetic Patients with Chronic Foot Ulcers (HODFU) study showed beneficial effect of HBOT. As this treatment is expensive and time-consuming, being able to select patients for therapy would be very useful. The aim of this study was to evaluate whether circulatory variables could help in predicting outcome of HBOT.

Methods All HODFU study participants who completed therapy, predefined as receiving at least 36 out of 40 scheduled HBOT/placebo sessions, were included in this study $(n=75)$. Baseline transcutaneous oximetry $\left(\mathrm{TcPO}_{2}\right)$, toe blood pressure (TBP) and ankle-brachial index (ABI) were measured. Ulcer healing rate was registered at the 9-month follow-up visit. An ulcer was considered healed when it was completely epithelialised and remained so at the 12-month follow-up.
\end{abstract}

Electronic supplementary material The online version of this article (doi:10.1007/s00125-010-1946-y) contains supplementary material, which is available to authorised users.

\footnotetext{
M. Löndahl $\cdot$ P. Katzman · M. Landin-Olsson

Institution for Clinical Sciences in Lund, Lund University,

Lund, Sweden

M. Löndahl $(\square)$

Department of Endocrinology, Skane University Hospital,

S 22185 Lund, Sweden

e-mail: magnus.londahl@med.lu.se

C. Hammarlund

Department of Anesthesiology, Helsingborg Hospital,

Helsingborg, Sweden

A. Nilsson

Department of Internal Medicine, Ängelholm Hospital,

Ängelholm, Sweden
}

Results In the HBOT group $\mathrm{TcPO}_{2}$ were significantly lower for patients whose ulcer did not heal as compared with those whose ulcers healed. A significantly increased healing frequency was seen with increasing $\mathrm{TcPO}_{2}$ levels in the HBOT group $\left(\mathrm{TcPO}_{2} /\right.$ healing rate: $<25 \mathrm{mmHg} / 0 \%$; $26-50 \mathrm{mmHg} / 50 \% ; 51-75 \mathrm{mmHg} / 73 \%$; and $>75 \mathrm{mmHg} /$ $100 \%$ ). No statistically significant relation between the level of TBP or ABI and healing frequency was seen. Conclusions/interpretation Our results indicate that $\mathrm{TcPO}_{2}$ in contrast to $\mathrm{ABI}$ and TBP correlates to ulcer healing following HBOT. We suggest HBOT as a feasible adjunctive treatment modality in diabetic patients with chronic non-healing foot ulcers when basal $\mathrm{TcPO}_{2}$ at the dorsum of the foot is above $25 \mathrm{mmHg}$.

Trial registration NCT00953186

Funding Mrs Thelma Zoegas Foundation and Faculty of Medicine, Lund University.

Keywords ABI - Chronic hyperbaric oxygen therapy · Diabetes $\cdot$ Foot ulcer $\cdot \mathrm{TcPO}_{2} \cdot$ Toe blood pressure

$\begin{array}{ll}\text { Abbreviations } \\ \text { ABI } & \text { Ankle-brachial index } \\ \text { HBOT } & \text { Systemic hyperbaric oxygen therapy } \\ \text { HODFU } & \text { Hyperbaric oxygen treatment in diabetic patients } \\ & \text { with chronic foot ulcers } \\ \text { TBP } & \text { Toe blood pressure } \\ \mathrm{TcPO}_{2} & \text { Transcutaneous oximetry }\end{array}$

\section{Introduction}

Systemic hyperbaric oxygen therapy (HBOT) has been suggested as a treatment for diabetic foot ulcers [1-3]. This 
treatment modality is expensive and time consuming, so being able to predict which patients will benefit from therapy would be very useful [4].

In the randomised, double-blind, placebo-controlled Hyperbaric Oxygen Treatment in Diabetic Patients with Chronic Foot Ulcers (HODFU) study, the effect of HBOT in diabetic patients with chronic foot ulcers Wagner grade 2, 3 and 4 was compared with the effect of hyperbaric air therapy (placebo) [5]. This study showed a beneficial effect of HBOT [6]. Therefore, we evaluated whether baseline arterial toe blood pressure (TBP), ankle-brachial index (ABI) or transcutaneous oximetry $\left(\mathrm{TcPO}_{2}\right)$ could help in predicting the effect of HBOT.

\section{Methods}

Design and rationale of the HODFU study and results of ulcer healing outcome have been reported in detail previously $[5,6]$. All HODFU study participants who completed therapy, predefined as receiving at least 36 out of 40 scheduled HBOT/placebo sessions, were included in this study $(n=75$ out of 94). Baseline characteristics are given in Electronic supplementary material (ESM) Table 1.

The protocol was approved by the Ethics Committee at Lund University, Sweden. All participants provided written informed consent.

$\mathrm{TcPO}_{2}$ measurements $\mathrm{TcPO}_{2}$ measurements were obtained with a Radiometer TCM2 (Radiometer, Copenhagen, Denmark) device. Calibration was performed before each measurement. All measurements were performed at 1 ATA and in supine position after $20 \mathrm{~min}$ of rest. Room temperature was kept between $21^{\circ} \mathrm{C}$ and $24^{\circ} \mathrm{C}$. Patients were asked to avoid smoking or drinking coffee for at least $2 \mathrm{~h}$ before investigations.

According to our protocol, $\mathrm{TcPO}_{2}$ was measured on the dorsum of the foot, $2 \mathrm{~cm}$ proximal to the base of the third toe, or as close to this location as possible. Areas directly overlying bone or superficial veins were avoided. The measuring site was carefully cleaned and the electrochemical transducer was then applied to the skin using adhesive rings and contact liquid supplied by the manufacturer. To increase skin oxygen permeability the transducer was heated to $42^{\circ} \mathrm{C}$. After baseline equilibration, $\mathrm{TcPO}_{2}$ values were recorded once every minute while the patient was breathing room air for $6 \mathrm{~min}$, followed by $100 \%$ oxygen for another $6 \mathrm{~min}$. The highest $\mathrm{Tc}_{\mathrm{CO}}$ values while breathing air or oxygen were chosen as the basal and stimulated $\mathrm{TcPO}_{2}$, respectively.

Methods for measuring TBP and ABI have been described previously [6].
Statistics Comparisons were tested with Mann-Whitney $U$ test. Correlations were tested with Pearson's test of correlations. Differences in frequencies were analysed with Fisher's exact test. A binary logistic regression was used to evaluate factors influence on outcome, with healing as the dependent variable.

A two-sided $p$ value below 0.05 was considered statistically significant. Statistical analysis was performed using Statistica software, version 9.0 (Statsoft Inc, Tulsa, OK, USA).

\section{Results}

In total, 75 patients were included in the study: 38 randomised to HBOT, 37 to placebo treatment. Patients' baseline characteristics did not differ between HBOT and placebo [6]. Median ulcer duration at inclusion was 11.8 and 10.3 months (HBOT vs placebo, NS). TBP, ABI and basal/stimulated $\mathrm{TcPO}_{2}$ at 1 ATA did not significantly differ between the HBOT and placebo groups.

There was a statistically significant correlation between TBP and ABI $\left(r^{2}=0.42, p=0.0003, n=68\right)$, and between basal and stimulated $\mathrm{TcPO}_{2}\left(r^{2}=0.53, p<0.000001, n=75\right)$. By contrast, no significant correlation was seen between TBP or $\mathrm{ABI}$ and $\mathrm{TcPO}_{2}$.

In the HBOT group, basal and stimulated $\mathrm{TcPO}_{2}$ were significantly lower for patients whose ulcer did not heal (non-healers) compared with those whose ulcers healed (healers) (Fig. 1). A statistically significant increased healing frequency was seen at higher $\mathrm{TcPO}_{2}$ levels (Fig. 2). These findings are also valid for the HBOT group in the intention-to-treat population of the HODFU study. No statistically significant relation between the level of $\mathrm{TBP}$ or $\mathrm{ABI}$ and healing frequency was seen. In the placebo group, basal and stimulated $\mathrm{TcPO}_{2}$ values were similar for healers compared with non-healers. In a binary regression analysis healers were compared with non-healers, including basal and stimulated $\mathrm{TcPO}_{2}, \mathrm{TBP}, \mathrm{ABI}$, age, diabetes duration and ulcer depth according to the Wagner classification scale. In the HBOT group basal $\mathrm{TcPO}_{2}$ was significantly related to ulcer healing (data not shown).

\section{Discussion}

Vascular complications in diabetes might be considered secondary to impaired macro- and/or microvascular disease. Both ABI and TBP are used in the evaluation of macrovascular circulation. $\mathrm{TcPO}_{2}$, being a composite measure of several factors such as arterial pressure, arterial oxygen content, local tissue perfusion pressures, neurovascular 

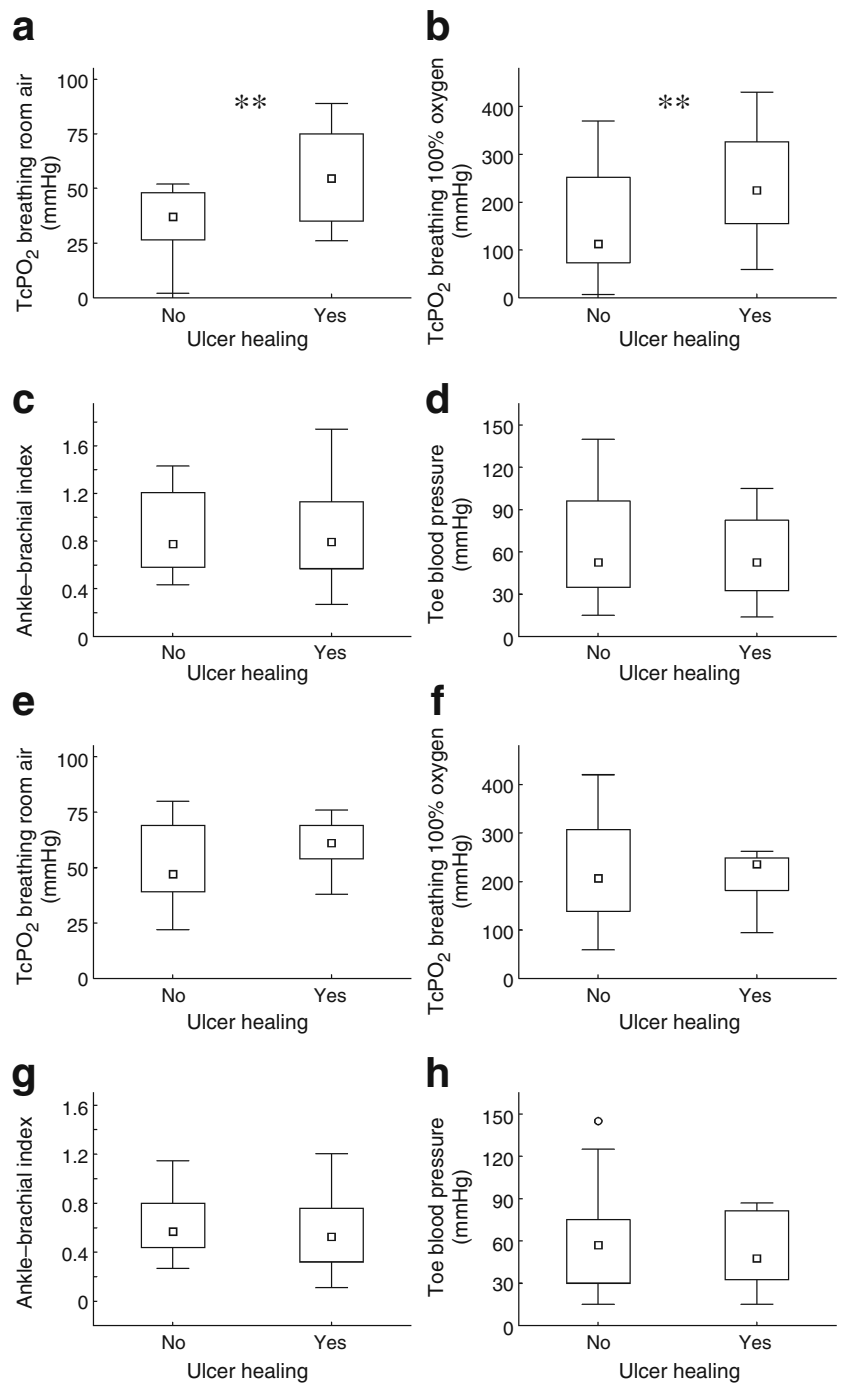

Fig. 1 Median basal $\mathrm{TcPO}_{2}$, stimulated $\mathrm{TcPO}_{2}$, TBP and $\mathrm{ABI}$ in patients with healed foot ulcers compared with patients with unhealed foot ulcers at 9-month follow-up after HBOT (a-d) or placebo (e-h), respectively. Data given as median, $25-75 \%$ and non-outlier min$\max . * * p<0.01$

function and local oxygen consumption, may be a more relevant measure, as it seems to reflect micro- as well as macrocirculation. $\mathrm{TcPO}_{2}$ has previously been shown to be related to outcome in diabetic foot ulcers [7]. Case series indicate that $\mathrm{TcPO}_{2}$ might be a predictor for healing after HBOT, but large comparative studies are still lacking. In our diabetic patients no correlation between foot ulcer healing and ABI was seen. Similarly, ABI was not reported as a factor influencing outcome of lower-extremity diabetic ulcers in a retrospective study including 1,006 patients from five hyperbaric facilities in the USA [8]. However, an absolute ABI value reduction of 0.1 was associated with a 1.7 times increased risk of major amputation in a randomised study by Faglia et al. [1]. Most studies evaluating the effect of HBOT on diabetic foot ulcers do not report TBP. In our study TBP could not be used as a predictor for ulcer healing, which is in agreement with the study by Kalani et al., in which major amputation was performed in nine (of 38) patients, with TBP normal in four, moderately decreased in three and severely decreased in two [3]. In our study, basal $\mathrm{TcPO}_{2}$ was significantly correlated with ulcer healing. Healing rates following HBOT decreased with decreasing basal $\mathrm{TcPO}_{2}$. No ulcer healed when basal $\mathrm{TcPO}_{2}$ was $<25 \mathrm{~mm}$ and all ulcers healed when $\mathrm{TcPO}_{2}$ was $>75 \mathrm{mmHg}$. In patients with $\mathrm{TcPO}_{2} 26-50$ and 51$75 \mathrm{mmHg}$, healing rates were $50 \%$ and $73 \%$, respectively. Similar results have been reported by others. In a study by Fife et al., 629 patients with basal $\mathrm{TcPO}_{2}$ below $25 \mathrm{mmHg}$ were less likely to benefit from HBOT than those with higher $\mathrm{TcPO}_{2}$ values [9]. Wattel et al. reported a mean basal $\mathrm{TcPO}_{2}$ of $32 \mathrm{mmHg}$ in healers $(n=15)$, compared with $12 \mathrm{mmHg}$ in non-healers in a case-series of 20 patients (11 with diabetes and nine arterial insufficiency without diabetes) given adjunctive treatment with HBOT [10]. In a retrospective study of 35 patients who received 16-20 sessions of HBOT after partial foot amputation, healing was achieved in all patients with a $\mathrm{TcPO}_{2}$ above $29 \mathrm{mmHg}$ [11]. Oubre et al. performed a retrospective analysis of 73 HBOT-treated patients (37 with diabetes) with 85 chronic lower extremity ulcers [12]. Robust healing was achieved in 33 ulcers, minimal healing in 33 and no healing in 21 . Basal mean $\mathrm{TcPO}_{2}$ in each of those groups were $57 \mathrm{mmHg}$, $44 \mathrm{mmHg}$ and $38 \mathrm{mmHg}$, respectively. In the present study, stimulated $\mathrm{TcPO}_{2}$ was significantly higher in healers compared with non-healers. However, in a regression analysis, stimulated $\mathrm{TcPO}_{2}$ was not superior to basal $\mathrm{TcPO}_{2}$ in predicting ulcer healing. In the placebo group - mirroring routine clinical care- $-\mathrm{TcPO}_{2}$ was of no prognostic value, possibly owing to a lower healing rate.

Although $\mathrm{TcPO}_{2}$ appears to be more useful as a prognostic factor for HBOT outcome than TBP and ABI, the method

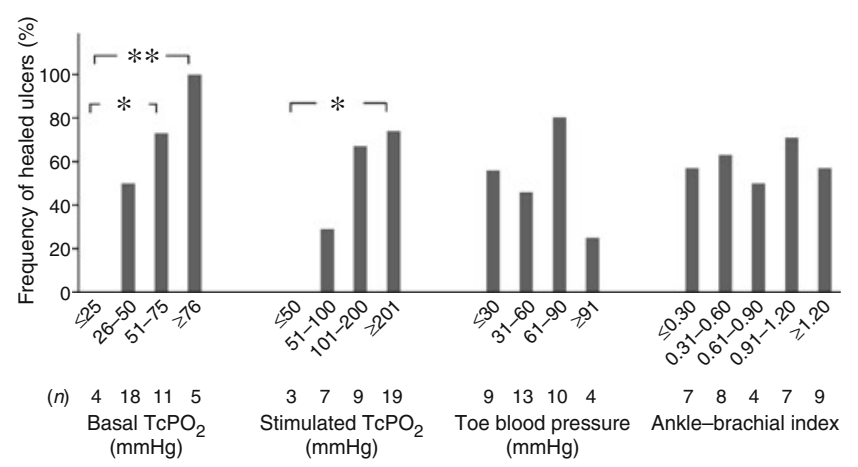

Fig. 2 Ulcer healing frequency at the 9-month follow-up according to basal $\mathrm{TcPO}_{2}$, stimulated $\mathrm{TcPO}_{2}, \mathrm{TBP}$ and $\mathrm{ABI}$ in patients who received HBOT $(n=38) . * p<0.05, * * p<0.01$ 
has several limitations. Measurements might be hampered by individual factors, such as electrode localisation, skin thickness and skin oxygen consumption, as well as ointments. Variation in patients' respiratory or cardiac condition may influence $\mathrm{TcPO}_{2}$, and the presence of oedema could be an important confounding factor. In our study $7 \%$ of $\mathrm{TcPO}_{2}$ measurements were postponed for oedema reduction including transient soft tissue infection. Skin heating reduces the barrier to transcutaneous diffusion of oxygen, and even small changes in temperature might have an impact on $\mathrm{TcPO}_{2}$. A heating element keeps a constant electrode temperature, usually between $42^{\circ} \mathrm{C}$ and $45^{\circ} \mathrm{C}$. At our hyperbaric unit, skin blistering and ulcer development have been seen as adverse reactions to $\mathrm{TcPO}_{2}$ measurement at $44^{\circ} \mathrm{C}$. As a consequence, we use a transmitter temperature of $42^{\circ} \mathrm{C}$, which might give $2-6 \%$ lower $\mathrm{TcPO}_{2}$ values compared with those taken at $44^{\circ} \mathrm{C}$. Arguments have been raised in favour of $\mathrm{TcPO}_{2}$ measurement at hyperbaric conditions as a better way to predict benefit from HBOT in diabetic patients with chronic foot ulcers. We did not use this method in our study, because it is not practical in a diabetic foot clinic.

In conclusion, these results indicate that basal and stimulated $\mathrm{TcPO}_{2}$ in contrast to $\mathrm{ABI}$ and $\mathrm{TBP}$, correlate to ulcer healing following HBOT. Further, we suggest hyperbaric oxygen therapy as a feasible adjunctive treatment modality in selected diabetic patients with chronic non-healing foot ulcers when basal $\mathrm{TcPO}_{2}$ at the dorsum of the foot is above $25 \mathrm{mmHg}$.

Acknowledgements The authors are grateful to J. Jeffery for scientific advice and help with the English text; to registered nurse C. Johansson and assistant nurses G. Torildsson and M. Andersson at the Hyperbaric Unit for collaboration and invaluable help. This study was supported by unrestricted grants from Zoégas Foundation, Region Skåne Foundation and the Medical Faculty of Lund University.

Duality of interest The authors declare that there is no duality of interest associated with this manuscript.

\section{References}

1. Faglia E, Favales F, Aldeghi A et al (1996) Adjunctive systemic hyperbaric oxygen therapy in treatment of severe prevalently ischemic diabetic foot ulcer. A randomized study. Diabetes care 19:1338-1343

2. Hinchliffe RJ, Valk GD, Apelqvist J et al (2008) A systematic review of the effectiveness of interventions to enhance the healing of chronic ulcers of the foot in diabetes. Diabetes Metab Res Rev 24(Suppl 1):S119-S144

3. Kalani M, Jorneskog G, Naderi N, Lind F, Brismar K (2002) Hyperbaric oxygen (HBO) therapy in treatment of diabetic foot ulcers. Long-term follow-up. J Diabetes Complications 16:153158

4. Roeckl-Wiedmann I, Bennett M, Kranke P (2005) Systematic review of hyperbaric oxygen in the management of chronic wounds. Br J Surg 92:24-32

5. Löndahl M, Katzman P, Nilsson A et al (2006) A prospective study: hyperbaric oxygen therapy in diabetics with chronic foot ulcers. J Wound Care 15:457-459

6. Löndahl M, Katzman P, Nilsson A, Hammarlund C (2010) Hyperbaric oxygen therapy facilitates healing of chronic foot ulcers in patients with diabetes. Diabetes care 33:998-1003

7. Kalani M, Brismar K, Fagrell B, Ostergren J, Jorneskog G (1999) Transcutaneous oxygen tension and toe blood pressure as predictors for outcome of diabetic foot ulcers. Diabetes care 22:147-151

8. Fife CE, Buyukcakir C, Otto G, Sheffield P, Love T, Warriner R 3rd (2007) Factors influencing the outcome of lower-extremity diabetic ulcers treated with hyperbaric oxygen therapy. Wound Repair Regen 15:322-331

9. Fife CE, Buyukcakir C, Otto GH et al (2002) The predictive value of transcutaneous oxygen tension measurement in diabetic lower extremity ulcers treated with hyperbaric oxygen therapy: a retrospective analysis of 1,144 patients. Wound Repair Regen 10:198-207

10. Wattel F, Mathieu D, Coget JM, Billard V (1990) Hyperbaric oxygen therapy in chronic vascular wound management. Angiology 41:59-65

11. Zgonis T, Garbalosa JC, Burns P, Vidt L, Lowery C (2005) A retrospective study of patients with diabetes mellitus after partial foot amputation and hyperbaric oxygen treatment. J Foot Ankle Surg 44:276-280

12. Oubre CM, Roy A, Toner C, Kalns J (2007) Retrospective study of factors affecting non-healing of wounds during hyperbaric oxygen therapy. J Wound Care 16:245-250 